The Egyptian Journal of Hospital Medicine (October 2020) Vol. 81 (1), Page 1255-1261

\title{
Insulin-Like Growth Factor Binding Protein-1 versus Cervical Length in Prediction of Successful Induction of Labor after 37 Week. Observational Study \\ Ibrahim Saif Elnasr*1, Dalia Sabry Mohamed Said ${ }^{1}$, Thoria Ahmed Omar' ${ }^{2}$, Hesham Ammar ${ }^{1}$ \\ Departments of ${ }^{1}$ Obstetrics and Gynecology and ${ }^{2}$ Clinical Pathology, \\ Faculty of Medicine, Menoufia University Menoufia Governorate, \\ Egypt. \\ *Corresponding author: Ibrahim Saif Elnasr, Mobile: (+20) 01003086747, E-Mail: ibrahimalisaifelnasr@ gmail.com
}

\section{ABSTRACT}

Background: Bishop Score is still the usual method to expect the results of labor induction. Transvaginal ultrasonographic measurement of cervical length (TVUS-CL) is more objective and insulin like growth factor binding protein-1(IGFBP-1) has been recently used for this aim.

Objective: This study was conducted to compare between TVUS-CL and detection of cervical (IGFBP-1) for prediction of results of induction of labor after 37 week of pregnancy.

Patients and Methods: A prospective cohort study on 140 pregnant women underwent induction of labor. All patients were subjected to TVUS-CL and detection of cervical (IGFBP-1) and Bishop Score. The primary outcome measure was induction success. The secondary outcome measure was induction to delivery interval.

Results: In our study (97) females delivered by simple vaginal delivery (SVD), (79) females delivered within 24 hour of induction, (18) females delivered after 24 hour, and (43) females delivered by caesarian section. The mean cervical length measured by TVUS in females who delivered by SVD was $24.89 \pm 5.48 \mathrm{~mm}$ and was $26.79 \pm 3.06 \mathrm{~mm}$ in those who delivered by CS. IGFBP-1 was positive in 71 females who delivered by SVD and in 17 females who delivered by CS and it was negative in 26 females who delivered by SVD and 26 females who delivered by CS.

Conclusion: Success of labor induction correlated significantly with detection of cervical IGFBP-1 and measurement of cervical length by TVUS.

Keywords: Induction of labor, Bishop Score, Transvaginal ultrasonographic measurement, cervical length, IGFBP-1.

\section{INTRODUCTION}

Induction of labor is used in about $20 \%$ of all deliveries and success of induction is thought to be dependent on cervical conditions, or ripeness ${ }^{(\mathbf{1})}$. To date, Bishop Score is still the standard method to predict the duration and outcome of induced labor. However, the pre induction favorability of the cervix as measured by the Bishop score is very subjective and many researches hade shown a low predictive value for the induction outcome especially in women with a small Bishop score ${ }^{(2)}$. TVUS-CL is a more objective tool for knowing cervical status ${ }^{(3)}$. Recently a bedside test for phosphorylated isoforms of IGFBP1 has been used to expect successful labor induction (4) The aim of our study was to do comparison between TVUS-CL and detection of IGFBP-1 by Actim Partus test in cervical secretions for prediction of successful induction of labor after 37 weeks of pregnancy.

\section{PATIENTS AND METHODS}

This is prospective cohort study conducted on 140 pregnant women underwent induction of labor for various indications. The cases were recruited from Obstetric Department of Menoufia University Hospital, Shibin El-Kom City, Menoufia Governorate, Egypt in the period from March to December 2019.

Ethical approval: The study protocol was approved by Hospital Local Medical Ethics Committee, Faculty of Medicine, Menoufia

\section{University (May 2019).}

An informed consent was obtained from all study participants after explanation the nature and scope of the study.

After exclusion of women with multifetal pregnancies, mal presentations, intrauterine fetal death (IUFD), placenta previa, major degree of cephalopelvic disproportion, non-reassuring cardiotocography (CTG), active genital herpes or invasive cervical cancer which contraindicate vaginal delivery, extreme low birth weight defined as less than $1500 \mathrm{~g}$, previous surgeries on the cervix (e.g. cautery, cervical amputation or conization), premature rupture of membranes (PROM), antepartum hemorrhage and patients in active labor on admission.

Our study included patients with singleton pregnancies after 37 weeks, women bearing a living fetus, fetuses with a cephalic presentation, no history of previous CS or myomectomy and intact membrane.

All women were subjected to complete history taking, general examination, routine laboratory investigations, ultrasound examination and specific laboratory investigations.

Detection of cervical IGFBP-1:

The test was used: IGFBP-1 was detected using Actim Partus test (Actim Noljakantie 13. FI-80130 Joensuu, Finland). 


\section{Specimen collection:}

A sterile Cusco speculum was inserted into the vagina. While the patients were in the lithotomy position, cervix was sterilized with antiseptic solution; sterile polyester swab was inserted into the cervical os for 10-15 seconds to allow it to absorb the secretion specimen. The swab was swirled vigorously in the extraction solution for 10-15 seconds as in Fig 1, A to extract the specimen immediately. Swab was pressed against the specimen extraction solution tube wall to squeeze any remaining liquid out of the swab, and discarded after extraction, the yellow dipstick was placed into the extraction sample and held it there until we saw the liquid front enter the result area then removed from the solution and placed it in a horizontal position as in Fig 1.B.

\section{Interpretation of the results:}

The result was interpreted as positive as soon as two blue lines become visible in the result area. Negative result should be read at 5 minutes. If the test line and control line appeared, the test result was positive as in Fig. 1.C. If one blue line, the control line appeared, the test result was negative as in Fig 1.D.

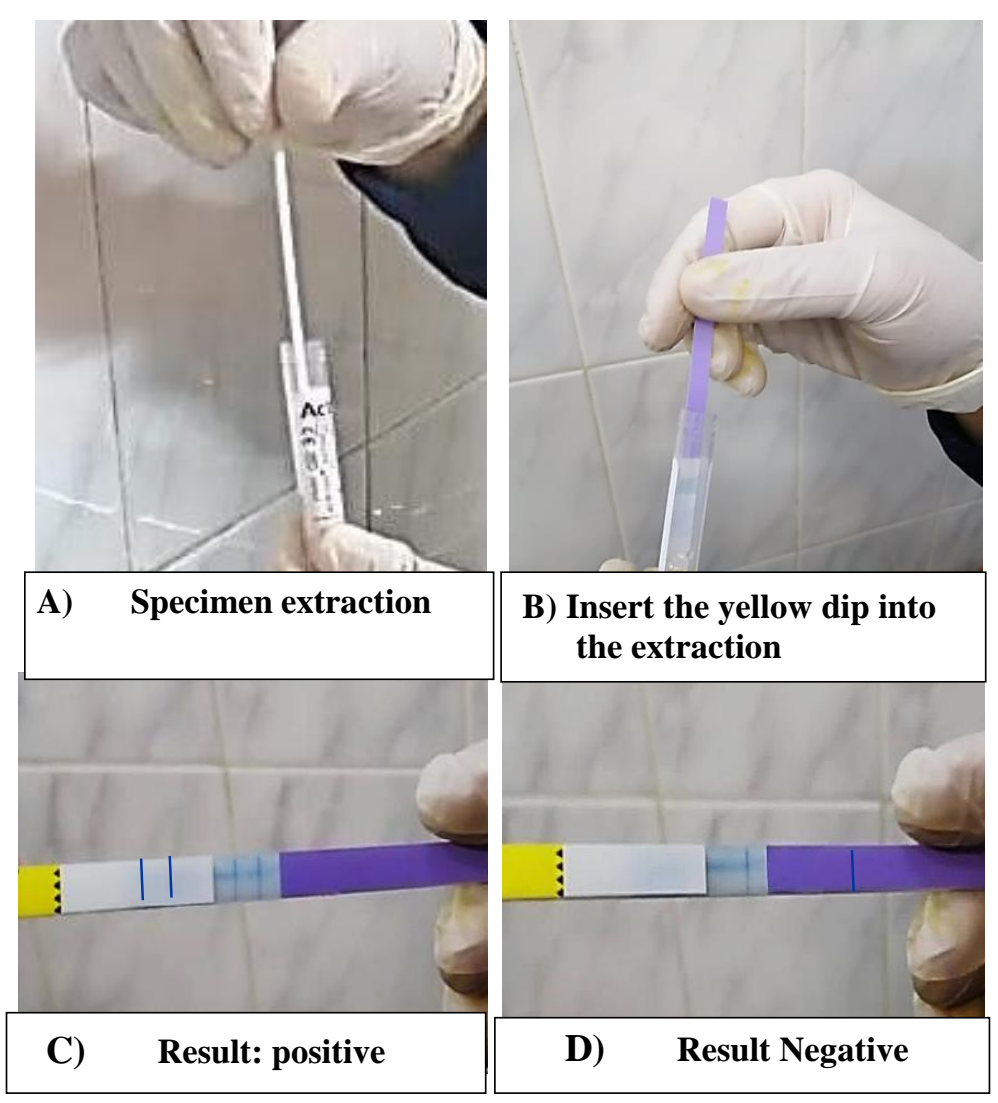

Fig (1): Actim Partus test; steps and results

Vaginal examination: To measure the Bishop score of the cervix, to exclude cephalopelvic disproportion, confirm presentation, position and detection of head station and to exclude contraindications of vaginal delivery.
Bishop scoring: Digital examination and scoring of the cervix using the modified bishop score was done.

Ultrasound evaluation of the cervix: Transvaginal U/S was done for cervical length measurement using 7.5 MHZ frequency of LOGIQ V5 machine (GE Medical Systems, China). The patient was asked to empty her bladder. The transvaginal probe was inserted into the vagina and rocked in the antero-posterior direction to visualize the cervix. The line of the internal cervical canal was visualized. Both lips of the cervix were checked to appear equal. The measurement was repeated three times and we recorded the average. The cervical length was measured from internal to external os. Induction of labor was done according to standard guidelines for labor induction.

The primary outcome measure was induction success (defined as the ability to achieve the active phase of labor; cervical dilation more than or equal to 4 centimeter).

The secondary outcome measure was induction to delivery interval (IDI).

Sample size: The sample size was calculated to be 140 women, according the formula, sample size (n) has been calculated based on specify $=\mathrm{Z}^{2}{ }_{1-\alpha / 2} \times \mathrm{SP} \times$ (1-SP) L2 ×(1-Prevalence).

\section{Statistical analysis}

Results were statistically analyzed by SPSS version 22 (SPSS Inc., Chicago, IL, USA). Independent $t$ test was used for parametric data. ChiSquared $\left(\chi^{2}\right)$ test was used for qualitative variables. Odds ratio (OR) and confidence interval (CI) $95 \%$ were also calculated. $\mathrm{P}$ value $<0.05$ was considered significant. Binary logistic regression was used to detect factors associated with increased likelihood of occurrence of cesarean section. Receiver operating characteristic (ROC curve) for detection of validity and cut off point was also used.

\section{RESULTS}

140 pregnant women between $37-42$ weeks of gestation underwent labor induction with mean age $23.34 \pm 4.09$ years, mean BMI was $29.12 \pm 2.57 \mathrm{~kg} / \mathrm{m}^{2}$ and mean gestational age $39.85 \pm 1.41$ weeks. The most common cause for labor induction was postdate (67), followed by pregnancy-induced hypertension (PIH) (40) then diabetes mellitus (33). Methods of induction was misoprostol in (75) females and amniotomy with oxytocin in (65) females. (97) Females delivered by simple vaginal delivery, (79) females delivered within 24 hour of induction, (18) females delivered after 24 hours, and

(43) females delivered by cesarean section (CS). Indications of CS were mainly due to failed induction and fetal distress. Figure (2). 


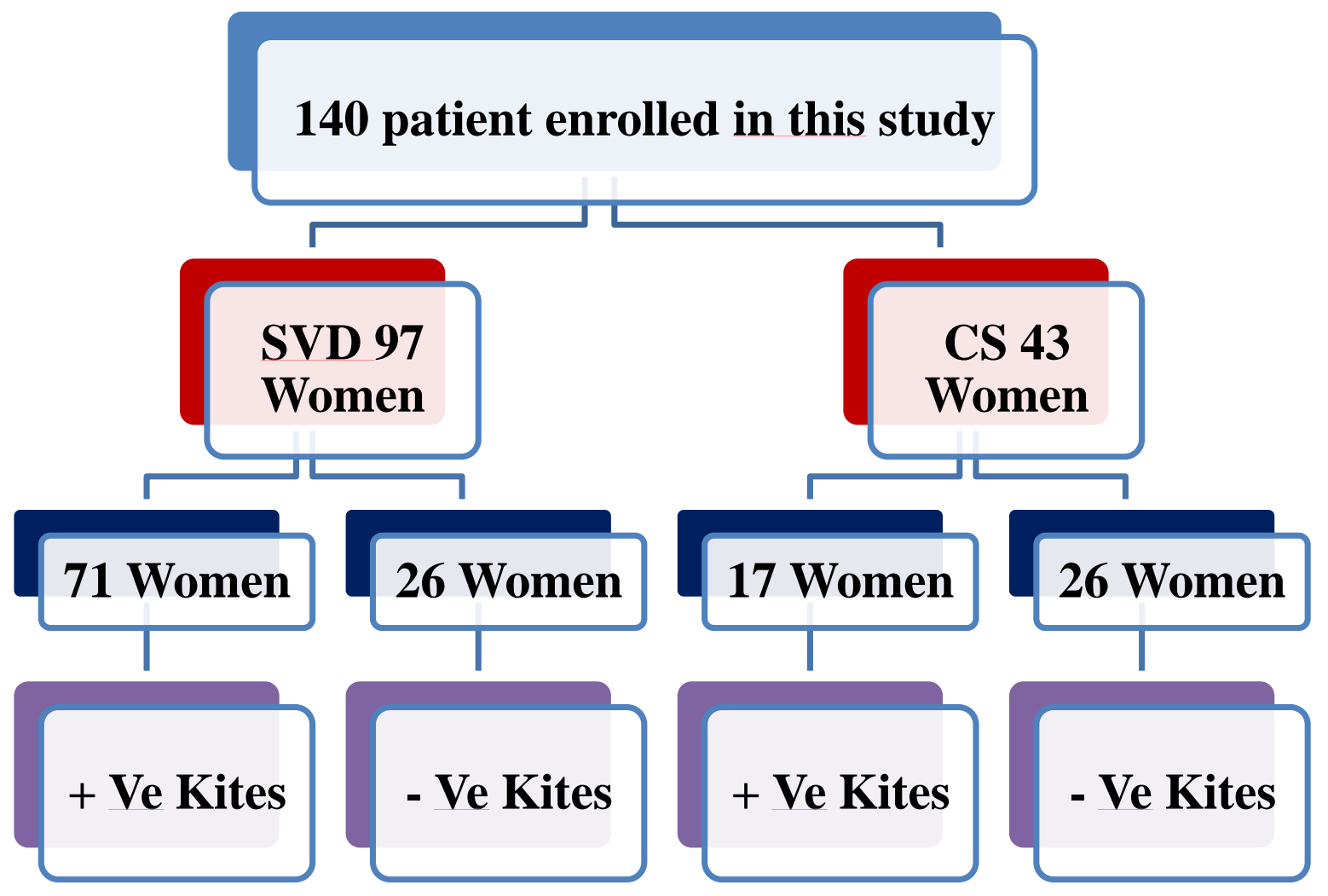

Fig. (2): Flow chart.

Table 1: Represent that the mean cervical length assessed by TVUS in females who delivered by SVD was 24.89 $\pm 5.48 \mathrm{~mm}$ and was $26.79 \pm 3.06 \mathrm{~mm}$ in those who delivered by C.S (non significant). IGFBP-1 was positive in 71 females who were delivered by SVD and in 17 females who were delivered by C.S. and it was negative in 26 females who were delivered by SVD and 26 females who were delivered by C.S (highly significant). Bishop score was $\geq 5$ in 82 females who were delivered by SVD and 21 females who were delivered by C.S, and it was $<5$ in 15 females were delivered by SVD and in 22 females delivered by C.S (highly significant).

Table (1): Distribution of the U/S cervical length and IGFBP-1 regarding studied mode of delivery.

\begin{tabular}{|c|c|c|c|c|c|c|c|}
\hline & \multicolumn{4}{|c|}{ Mode of delivery } & \multirow{3}{*}{$\begin{array}{l}\text { Test of } \\
\text { sig }\end{array}$} & \multirow{3}{*}{$P$ value } & \multirow{3}{*}{$\begin{array}{c}\text { OR } \\
\text { CI 95\% }\end{array}$} \\
\hline & \multicolumn{2}{|c|}{$\begin{array}{l}\text { Vaginal } \\
\text { No. }=97\end{array}$} & \multicolumn{2}{|c|}{$\begin{array}{c}\mathrm{CS} \\
\text { No. }=43\end{array}$} & & & \\
\hline & no & $\%$ & no & $\%$ & & & \\
\hline $\begin{array}{l}\text { U/S cervical length } \\
\text { Mean } \pm \text { SD }\end{array}$ & \multicolumn{2}{|c|}{$24.89 \pm 5.48$} & \multicolumn{2}{|c|}{$26.79 \pm 3.06$} & 2.13 & 0.035 & - \\
\hline $\begin{array}{l}\text { Cervical length } \\
\bullet \leq 27 \\
\bullet>27 \\
\end{array}$ & $\begin{array}{l}51 \\
46 \\
\end{array}$ & $\begin{array}{l}52.6 \\
47.4 \\
\end{array}$ & $\begin{array}{l}23 \\
20 \\
\end{array}$ & $\begin{array}{l}53.5 \\
46.5 \\
\end{array}$ & $\begin{array}{l}\chi^{2} \\
0.01\end{array}$ & 0.921 & $\begin{array}{c}1.0 \\
0.96(0.47-1.98)\end{array}$ \\
\hline $\begin{array}{l}\text { IGFBP-1:no,\% } \\
\text { - Positive } \\
\text { - Negative }\end{array}$ & $\begin{array}{l}71 \\
26\end{array}$ & $\begin{array}{l}73.2 \\
26.8\end{array}$ & $\begin{array}{l}17 \\
26\end{array}$ & $\begin{array}{l}39.5 \\
60.5\end{array}$ & $\begin{array}{c}\chi^{2} \\
14.46\end{array}$ & $<0.001$ & $\begin{array}{c}1.0 \\
4.18(1.96-8.92)\end{array}$ \\
\hline $\begin{array}{l}\text { Bishop score } \\
\bullet \geq 5 \\
\bullet<5\end{array}$ & $\begin{array}{l}82 \\
15\end{array}$ & $\begin{array}{l}84.5 \\
15.5\end{array}$ & $\begin{array}{l}21 \\
22\end{array}$ & $\begin{array}{l}48.8 \\
51.2\end{array}$ & $\begin{array}{c}\chi^{2} \\
19.52\end{array}$ & $<0.001$ & $\begin{array}{c}1.0 \\
5.73(2.54-12.91)\end{array}$ \\
\hline
\end{tabular}

OR: odds ratio. CI: Confidence interval 
Table 2: Showed that the mean of cervical length by TVUS was $24.02 \pm 5.71 \mathrm{~mm}$ in females who were delivered by SVD within $24 \mathrm{hr}$. and it was $28.72 \pm 1.01 \mathrm{~mm}$ in those who delivered by SVD after $24 \mathrm{hr}$ (highly significant). IGFBP-1 was positive by Actim partus test in 66 females who were delivered by SVD within $24 \mathrm{hr}$. and also positive 5 females who were delivered by SVD after 24hr. IGFBP-1was negative in 13 females who were delivered by SVD within $24 \mathrm{hr}$. and in 13 females who were delivered by SVD after 24hr (highly significant). Bishop score represent non significant statistical difference.

Table (2): Distribution of the U/S cervical length and IGFBP-1 regarding studied vaginal mode of delivery within 24 hours or after 24 hours.

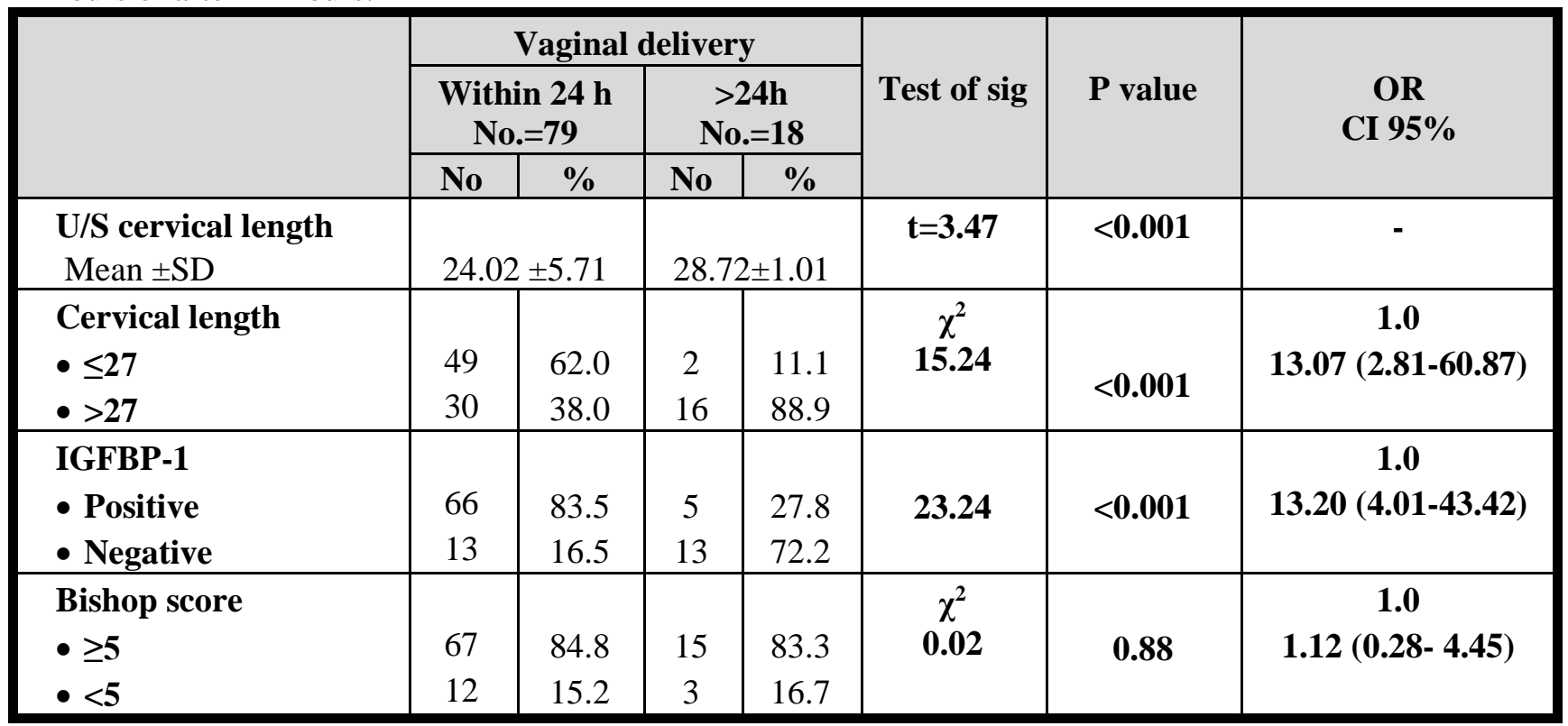

OR: odds ratio. CI: Confidence interval

Table 3 and figure (3): Shows that the area under the ROC curve (AUC) for Bishop Score at cut of value $\geq 5$ was 0.659 With sensitivity 0.85 , specificity 0.41 , Accuracy 0.66 , positive predictive value (PPV) 0.65 and negative predictive value (NPV) 0.68. As regarding cervical length at $\leq 27$ the AUC was 0.343 with Sensitivity 0.62 , specificity 0.89 , Accuracy 0.67 , PPV 0.96 and NPV 0.35 . In contrast to IGFBP-1 the AUC was 0. 349 with Sensitivity 0.84, specificity 0.64 , Accuracy 0.75, PPV 0, 75 and NPV 0.75 in females who delivered by SVD within 24 hr. Figure (3).

Table (3): Validity of IGFBP-1, Bishop Score, and cervical length by transvaginal ultrasound in the prediction of vaginal delivery within 24 hours.

\begin{tabular}{|l|c|c|c|c|c|c|}
\hline & $\begin{array}{c}\text { Cut off } \\
\text { value }\end{array}$ & Sensitivity & Specificity & Accuracy & PPV & NPV \\
\hline Bishop score & $\mathbf{( 2 5 )}$ & 0.85 & 0.41 & 0.66 & 0.65 & 0.68 \\
& & $0.75-0.92$ & $0.29-0.54$ & $0.57-0.73$ & $0.55-0.74$ & $0.50-0.81$ \\
\hline Cervical length & $\mathbf{2 7 m m}$ & 0.62 & 0.89 & 0.67 & 0.96 & 0.35 \\
& & $0.50-0.73$ & $0.64-0.98$ & $0.57-0.76$ & $0.85-0.99$ & $0.22-0.50$ \\
\hline IGFBP-1 & $\mathbf{( + v e )}$ & 0.84 & 0.64 & 0.75 & 0.75 & 0.75 \\
& & $0.73-0.91$ & $0.51-0.76$ & $0.67-0.82$ & $0.64-0.83$ & $0.61-0.86$ \\
\hline
\end{tabular}




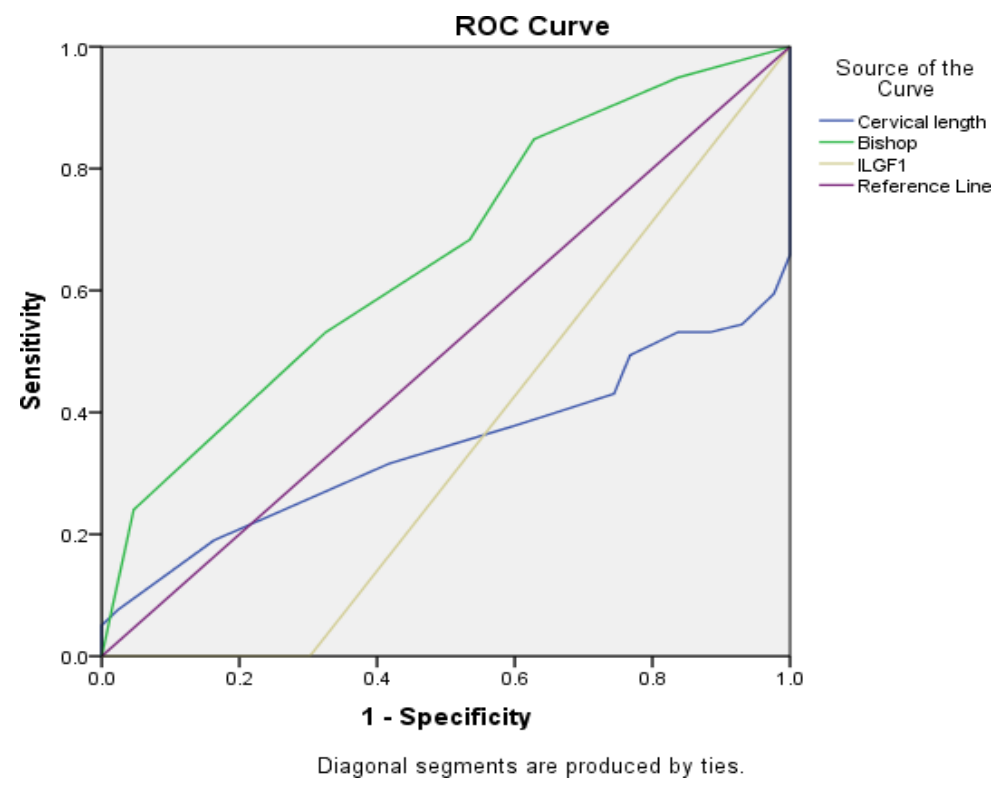

Fig (3): ROC curve in females who delivered by SVD within $24 \mathrm{hr}$.

Table 4 and figure (4): Showed the area under the ROC curve (AUC) for Bishop Score at cut of value $\geq 5$ was 0.506 with sensitivity 0.83 , specificity 15.0 , Accuracy 0.28 , PPV 0.18 and NPV 0.80 . As regarding cervical length at $\leq 27$ the AUC was 0.732 with Sensitivity 0.11 , specificity 0.38 , Accuracy 0.33 , PPV 0.04 and NPV 0.65 . In contrast to IGFBP-1 the AUC was 0.438 with Sensitivity 0.28 , specificity 0.16 , Accuracy 0.19 , PPV 0.07 and NPV 0.50 in females who delivered by SVD > 24 hours.

Table (4): Validity of IGFBP-1, Bishop Score, and cervical length by transvaginal ultrasound in the prediction of vaginal delivery $>24$ hours.

\begin{tabular}{|l|c|c|c|c|c|}
\hline & Sensitivity & Specificity & Accuracy & PPV & NPV \\
\hline \multirow{2}{*}{ Bishop score ( $\mathbf{5})$} & 0.83 & 15.0 & 0.28 & 0.18 & 0.80 \\
& $0.58-0.96$ & $0.08-0.25$ & $0.19-0.38$ & $0.11-0.29$ & $0.51-0.95$ \\
\hline \multirow{2}{*}{ Cervical length $(\leq \mathbf{2 7 m m )}$} & 0.11 & 0.38 & 0.33 & 0.04 & 0.65 \\
& $0.02-0.36$ & $0.27-0.50$ & $0.24-0.43$ & $0.01-0.15$ & $0.50-0.78$ \\
\hline \multirow{2}{*}{ IGFBP-1 (+ve) } & 0.28 & 0.16 & 0.19 & 0.07 & 0.50 \\
& $0.11-0.54$ & $0.09-0.27$ & $0.12-0.28$ & $0.30-0.70$ & $0.30-0.70$ \\
\hline
\end{tabular}

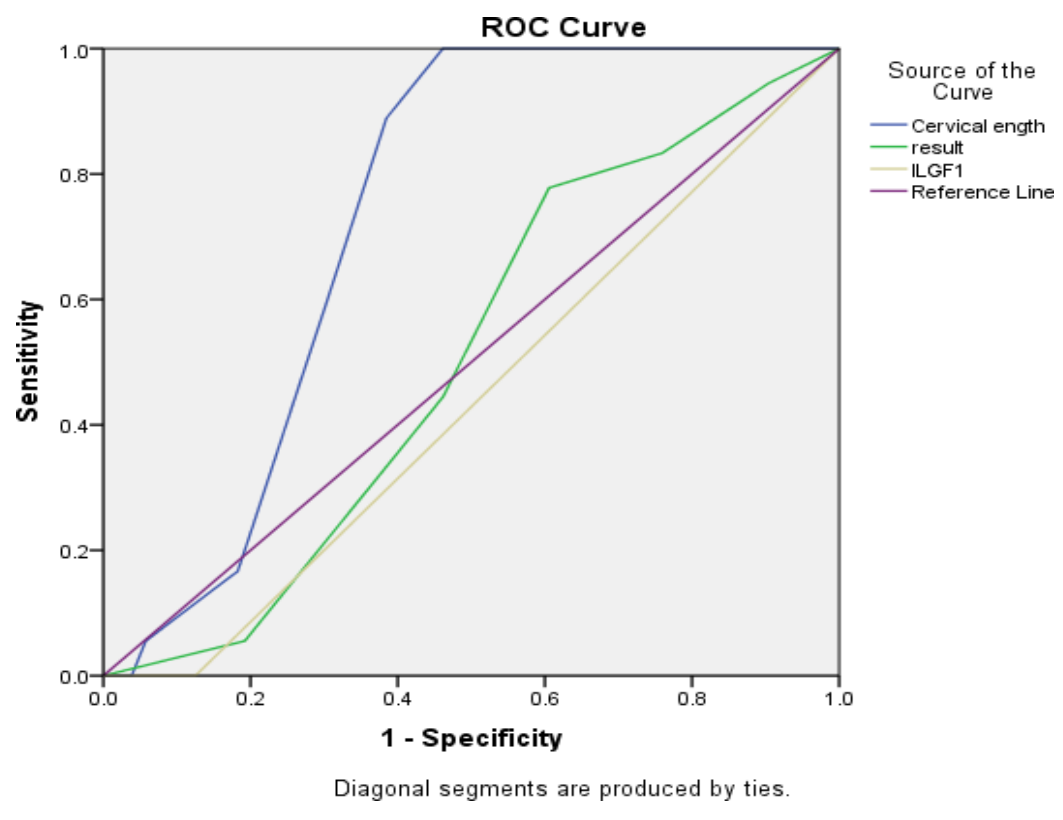

Fig (4): ROC curve in females who delivered by SVD after $24 \mathrm{hr}$. 
In Table 5: A logistic regression was performed to ascertain the effects of cervical length, bishop score and IGFBP1 on the likelihood that participants have CS. The logistic regression model was statistically significant, $\chi^{2}(4)=$ $36.07, \mathrm{P}<0.001$. The model explained $32.0 \%$ of the variance in CS and correctly classified $75.0 \%$ of cases. IGFBP1 (Negative) and Bishop Score $(<5)$ were 6.92 and 6.44 times respectively more expected to exhibit CS.

Table (5): Binary logistic regression for predictors of Mode of delivery.

\begin{tabular}{|l|c|c|c|c|}
\hline & \multirow{2}{*}{ OR } & \multirow{2}{*}{ P value } & \multicolumn{2}{|c|}{ 95\% CI } \\
\cline { 4 - 5 } & & & Lower & Upper \\
\hline Cervical length $(>\mathbf{2 7})$ & 0.37 & 0.086 & 0.12 & 1.15 \\
\hline Bishop score $(<\mathbf{5})$ & 6.44 & $<0.001$ & 2.60 & 15.98 \\
\hline IGFBP-1 (Negative) & 6.92 & $<0.001$ & 2.61 & 18.34 \\
\hline
\end{tabular}

\section{DISCUSSION}

In this study IGFBP-1 was more sensitive than cervical length which was measured by transvaginal ultrasound. The present study found that success of induction of labor correlated significantly with cervical length assessed by TVUS and IGFBP-1 kits were positive.

Gibreil et al. ${ }^{(5)}$, studied 200 women. TVUS was done for all participants prior to induction. The AUC calculated for Bishop score was 0.39 (95\% CL 0.30.48). The AUC for cervical length was 0.69 (95\% CL $0.6-0.77)$. Testing equality of the ROC curves for these two tools revealed that the ROC for cervical length was statistically different from Bishop score $(\mathrm{P}<0.001)$. Agreeing with our results they found cervical length measured by TVUS has potential to replace the traditional Bishop score, provided that such a facility is available when needed.

These results agreed with the study conducted by Vallikkannu et al. ${ }^{\left({ }^{(6)}\right.}$ on 193 women where IGFBP-1 was measured then TVUS and finally Bishop score. IGFBP-1 had $81 \%$ sensitivity, $59 \%$ specificity, positive and negative predictive values of 82 and $58 \%$, respectively, and positive and negative likelihood ratios of 2.0 and 0.3 for vaginal delivery, respectively ${ }^{\left({ }^{6}\right)}$.

Our results are consistent with the study conducted by Kosinska-Kaczynska et al. ${ }^{(7)}$ who studied 167 women. IGFBP-1 test, TVUS-CL and Bishop score were studied in the study group where $67.5 \%$ of patients delivered vaginally and $32.5 \%$ had cesarean section. IGFBP-1 test expected spontaneous labor onset (sensitivity 0.69 , specificity of 0.42 ) and success of vaginal delivery $(0.67,0.48)$. TVUS-CL and IGFBP-1 had comparable sensitivity in the prediction of spontaneous delivery onset. All three tests had comparable sensitivity in prediction of successful vaginal birth. The interval from pre induction to spontaneous onset of delivery was significantly less in women with positive IGFBP-1 test (13.65 \pm 6.7 vs. $20.75 \pm 2.6$ hour; $\mathrm{P}=0.006$ ).

Our results are in agreement with Dögl $\boldsymbol{e t}$ al. ${ }^{(8)}$ who studied on 391women, Bishop Score, TVUS-CL and IGFBP-1 test in prediction of spontaneous labor onset and successful induction. They found that with expectant management, IGFBP-1 expected spontaneous labor onset and delivery within 72 hours with small sensitivity and big specificity $(0.45$ and 0.80 , respectively), as with Bishop score $(0.24,0.92)$. Cervical length was more sensitive $(0.67,0.58)$. IGFBP-1 expected success of induction within 24 hours with small sensitivity and big specificity $(0.30,0.85)$; the same as Bishop score $(0.06,1.00)$ and TVUS-CL $(0.45,0.76)$. Parity enhanced successful induction.

Riboni et al. ${ }^{(9)}$ conducted study on 115 women revealed that the Bishop score, IGFBP-1 and IL-8 expected success of induction, and suggested that phIGFBP-1 test is a rapid and simple test that can be applied with the Bishop score and IL-8 to expect the successful labor induction with prostaglandin.

Our study is not consistent with the study conducted by Cheung et al. ${ }^{(10)}$ on 460 patients at 3741 weeks of gestations to determine TVUS-CL, posterior cervical angle (PCA) and the fetal occipital position. The Bishop score (BS) and IGFBP-1 test. A total $340(73.9 \%)$ patients had vaginal delivery following induction. Multivariate analysis indicated that significant independent predictors of vaginal delivery were CL. After assessment, they found that the combination of TVUS-CL and maternal characteristic was superior to either Bishop Score or TVUS cervical length alone to predict the induction outcome. The inclusion of IGFBP-1 didn't further improve prediction in their model. Their findings are very contradictory to ours, and the difference may result from the mixed population of nulliparous $(61 \%)$ and parous $(39 \%)$ women in their study. Also, $72 \%$ of their participants had their labor, induced because of prolonged pregnancy. In contrast, our participants were exclusively nulliparous and only $47.9 \%$ had labor induction for prolonged pregnancy ${ }^{(\mathbf{1 0})}$.

\section{CONCLUSIONS}

From this study we concluded that success of labor induction correlated significantly with presence of IGFBP-1 in cervical secretions and measurement of cervical length by TVUS, IGFBP-1 detection by Actim Partus test is simple, easy bedside test that can predict success of labor induction and TVUS-CL can be a good predictor factor for successful induction of labor.

\section{Strength of the study:}

Our study had large sample size and promising for prediction of success of labor induction with 
addition of IGFBP-1 to standard methods.

Limitation of this study: our study has some limitations

1. It only included primigravida females while other studies included both primigravida and multigravida females, so another study on multiparous group will be beneficial to evaluate the role of IGFBP-1 in prediction of success of labor induction.

2. IGFBP-1 by Actim Partus test is a supplementary test; it could bring more information for good patients' qualification for labor induction. However, it is not evaluated if the test could be used on economic basis. Although its cost effectiveness is yet to be determined, it seems that it could increase the costs of medical management.

\section{ACKNOWLEDGMENT}

We would like to acknowledge residents and nursing staff in the Obstetrics and Gynecology Department of Menoufia University Hospital for their contribution.

Disclosure of interest: The authors report no conflict of interest.

\section{REFERENCES}

1. Ezebialu I, Eke A, Eleje G et al. (2015): Methods for assessing pre- induction cervical ripening. Cochrane Database of Systematic Reviews, 6:16-19.

2. Hamm R, Downes K, Srinivas S et al. (2019): Using the probability of cesarean from a validated cesarean prediction calculator to predict labor length and morbidity. Am J Perinatol., 36(6):561-566.

3. Verhoeven C, Opmeer B, Oei S et al. (2013): Transvaginal sonographic assessment of cervical length and wedging for predicting outcome of labor induction at term: a systematic review and meta- analysis. Ultrasound in Obstetrics \& Gynecology, 42(5):500-8.

4. Chalurkar U, Andallu R (2017): Detection of prom using strip immuno assay test to detect insulin like growth factor binding protein-1 (IGFBP-1) in amniotic fluid in comparison with fern test. International Journal of Contemporary Medical Research, 4(5):1118-21.

5. Gibreil M, Elboghdady A, AL-Bohy A (2018): Transvaginal ultrasound measurement of cervical length and posterior cervical angle versus bishop scoring in assessment of induction of labour. Egyptian Journal of Hospital Medicine, 73(6):9-16.

6. Vallikkannu N, Lam W, Omar S et al. (2017): Insulin- like growth factor binding protein 1, Bishop score, and sonographic cervical length: tolerability and prediction of vaginal birth and vaginal birth within 24 hours following labour induction in nulliparous women. BJOG: An International Journal of Obstetrics \& Gynaecology, 124(8):1274-83.

7. Kosinska-Kaczynska K, Bomba-Opon D, Bobrowska K et al. (2015): Phosphorylated IGFBP-1 in predicting successful vaginal delivery in post-term pregnancy. Archives of Gynecology and Obstetrics, 292(1):45-52.

8. Dögl M, Skogvoll E, Heimstad R (2011): Cervical insulinlike growth factor binding protein- 1 (IGFBP- 1) to predict spontaneous onset of labor and induction to delivery interval in post- term pregnancy. Acta Obstetricia et gynecologica Scandinavica, 90(1):57-62.

9. Riboni F, Vitulo A, Dell'avanzo M et al. (2011): Biochemical markers predicting pre-term delivery in symptomatic patients: phosphorylated insulin-like growth factor binding protein-1 and fetal fibronectin. Arch Gynecol Obstet., 284(3):1325-1329.

10. Cheung C, Leung T, Sahota D et al. (2010): Outcome of induction of labour using maternal characteristics, ultrasound assessment and biochemical state of the cervix. The Journal of Maternal-Fetal \& Neonatal Medicine, 23(12):1406- 
